ENTREPRENEURSHIP AND SUSTAINABILITY ISSUES

ISSN 2345-0282 (online) http://jssidoi.org/jesi/

2019 Volume 6 Number 4 (June)

http://doi.org/10.9770/jesi.2019.6.4(30)

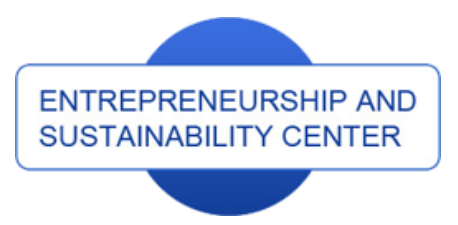

Publisher

http://jssidoi.org/esc/home

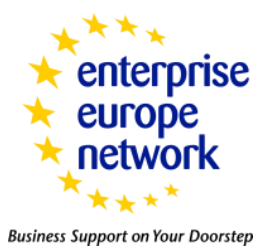

CASPA

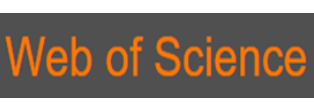

\title{
SUSTAINABLE ENERGY SYSTEMS IN THE DIGITAL ECONOMY: CONCEPT OF SMART MACHINES*
}

\author{
Andrey I. Vlasov', Vadim A. Shakhnov², Sergey S. Filin ${ }^{3}$, Aleksey I. Krivoshein ${ }^{4}$ \\ 1,2,4 Bauman Moscow State Technical University, \\ 5 Vtoraya Baumanskaj Str., Moscow, 105005, Russian Federation \\ ${ }^{2,4}$ LLC "Konnekt", \\ 2/15, Lasenki Str., Moscow, 119619, Russian Federation \\ E-mails:lasov@iu4.ru; shakhnov@bmstu.ru, c.e.p.e.r.a@mail.ru, alexeykrivoshein@mail.ru
}

Received 20 February 2019; accepted 5 May 2019; published 30 June 2019

\begin{abstract}
The concept of the creation of universal smart machines for power systems and critical infrastructure is discussed herein in terms of digital economy requirements. The functional requirements for a universal smart machine for sustainable energy systems are systematized based on a comparative analysis of technology. The requirements determine the approaches to the implementation of software, hardware and design solutions that provide diagnostics and monitoring of the energy state of infrastructures, systems for individual and collective power supply, life support systems of buildings, the state of household appliances, IoT devices, and devices of the housing and utilities sector. The recommendations on the constructive implementation of smart machines are given, making it possible to improve the existing approaches to quality assessment of the services provided in the energy industry. The concept of universal smart machines opens up the opportunities to increase the efficiency of providing the industry and households with a new type of information management services in the field of control over energy infrastructure as one of the main components of the digital economy.
\end{abstract}

Keywords: smart networks; Internet of things; digital economy; smart machine; monitoring; intelligent control.

Reference to this paper should be made as follows: Vlasov, A.I.; Shakhnov, V.A.; Filin, S.S.; Krivoshein, A.I. 2019. Sustainable energy systems in the digital economy: concept of smart machines, Entrepreneurship and Sustainability Issues 6(4): 1975-1986.

http://doi.org/10.9770/jesi.2019.6.4(30)

JEL Classifications: L94, Q40, O30

\section{Introduction}

The process of urbanization is increasing steadily, resulting in the intellectualization of the infrastructure (Akberdina et al., 2017; Petrenko et al., 2019). Creation of the technological basis for the development of the

\footnotetext{
* This research was conducted with the support of the Ministry of Science and Education of Russia within the framework of the project under Agreement No. 14.579.21.0158, ID RFMEFI57918X0158
} 
ENTREPRENEURSHIP AND SUSTAINABILITY ISSUES

ISSN 2345-0282 (online) http://jssidoi.org/jesi/

2019 Volume 6 Number 4 (June)

http://doi.org/10.9770/jesi.2019.6.4(..)

innovative infrastructure providing the diagnostics and monitoring of life support systems, the state of household appliances, and housing and communal service devices is becoming a highly relevant problem (Khelifi et al., 2018). This process is steadily associated with the development of technological solutions in the field of energy monitoring, predictive maintenance of industrial and social infrastructure (Kireev et al., 2018b; Berdyugina et al., 2018; Vlasov et al., 2017; Grigoriev et al., 2018).

One of the directions is the transition of electric power supply systems to the IoT concept (Berdyugina et al., 2018; Vlasov et al., 2017; TAdviser, 2018; Rentiuk, 2017; Roslyakov et al., 2015), which is a necessity in terms of rapid development of the digital economy. According to TAdviser, as of 2018, the number of connected Internet of Things devices in the world was about 2.1 billion, and it will exceed 5.0 billion by 2021/2022. Figure 1 shows the graphic representation of the number of connected IoT devices (TAdviser, 2018).

Connected Iot devices (billions)

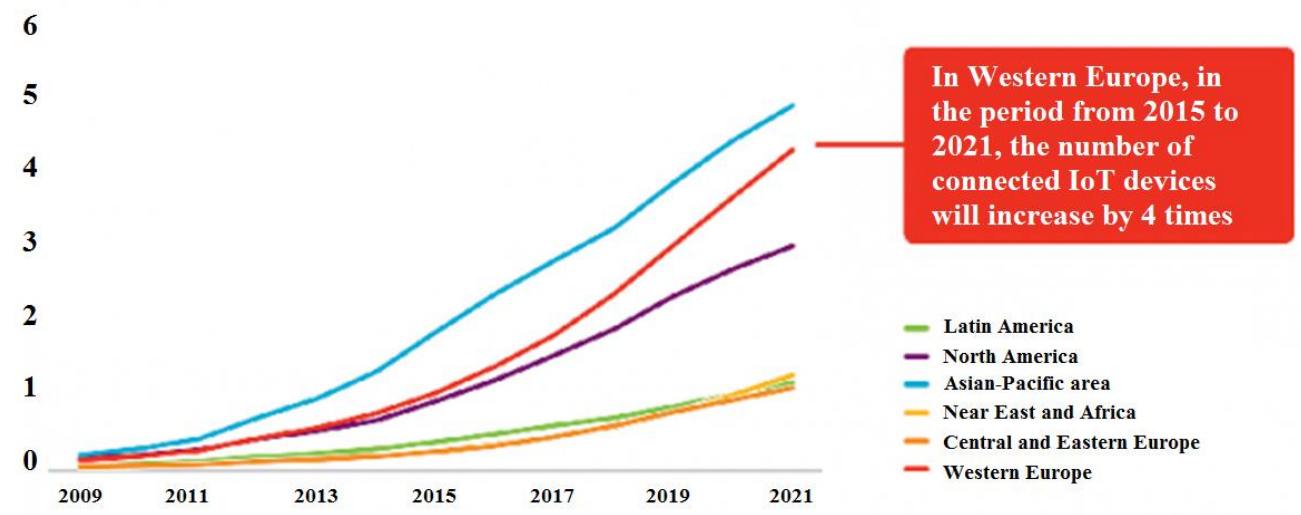

Fig. 1. Dynamics of the number of connected IoT devices

According to the graph, the components of intelligent infrastructure are becoming more common. Their implementation is primarily aimed at the improvement of the efficiency of production and social infrastructure. At the same time, the energy sector is dominant in solving the problems of the development of the digital economy. The most large-scale projects in this segment have been developed and implemented in the USA, Canada, the European Union countries, China, South Korea, and Japan. In particular, by 2020, China expects to reach the level of $90-95 \%$ in the equipment with modern energy accounting systems which is $50-60 \%$ in the USA. The energy policy of these countries implies full equipment with energy monitoring smart devices (TAdviser, 2018).

The analysis of the modern trends of the digital economy sets the problem of creating new autonomous smart devices using the blockchain technology (Swan, 2015), "cloud" and boundary computing (Lyapin, \& Finogeev, 2016; Barman, \& Ahmed, 2015; Edelev et al., 2018), which provide for remote diagnostics and monitoring of the energy status of the infrastructure facilities (Navigant Research, 2014; Kireev et al., 2018a). This determines the problem associated with digital data processing in various formats, different volumes, taking into account the frequency of their receipt. To solve this problem, various implementations of universal smart machines are becoming more and more common elements of modern intelligent data processing systems in the digital economy (Navigant Research, 2014; Eneca, 2018). 
ENTREPRENEURSHIP AND SUSTAINABILITY ISSUES

ISSN 2345-0282 (online) http://jssidoi.org/jesi/

2019 Volume 6 Number 4 (June)

http://doi.org/10.9770/jesi.2019.6.4(..)

\section{Literature review}

The problem of creation of a technological basis for the development of intelligent infrastructure in a digital economy can be solved only at the interface of such digital technologies as Smart Space, Smart Grid, Smart City, Smart House, Smart Sensor, Smart Transport, Internet of Things and Industrial Internet, Big Data, Intelligent Data Analysis (Figure 2) (Tupchienko, 2018; Lee et al., 2017). The technological basis itself is included in the concept of Smart Control, which provides registration, accounting and intelligent processing of data from digital smart devices.

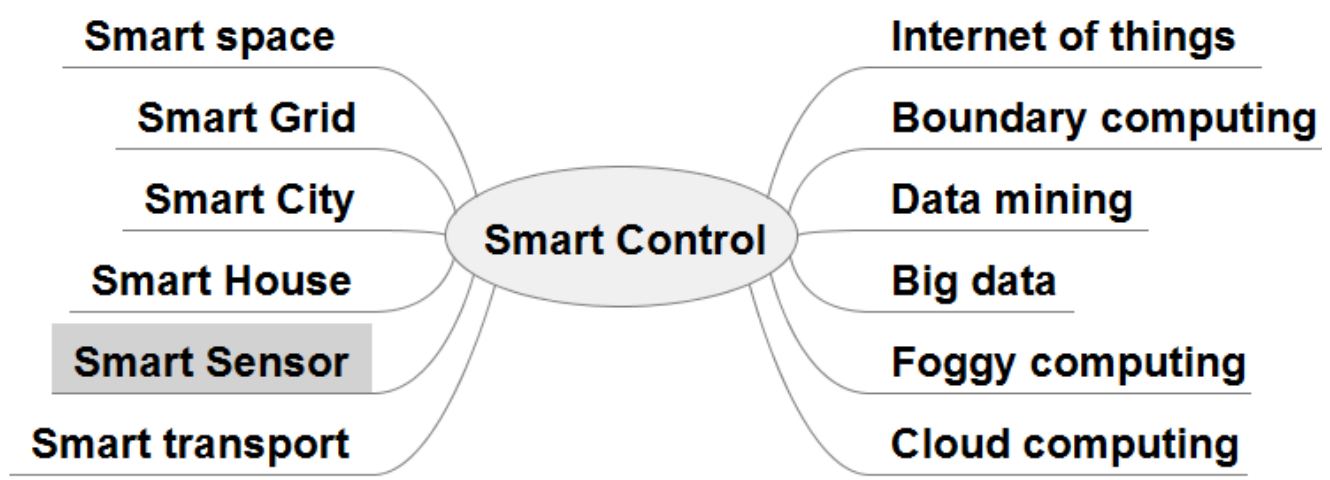

Fig. 2. The relationship of technology to create a technological basis for the development of intellectual-digital data collection infrastructure

Currently, the energy sector is undergoing a period of global change. The Smart Grid concept is the main trend affecting the development of information systems in the energy sector (TAdviser, 2018). The Smart Grid technological solutions can be divided into several key areas: (1) measuring devices and facilities, including, primarily, smart meters and smart sensors (Vasiliev, \& Chernov, 2012; Andreev et al., 2016); (2) improved management practices (Tupchienko, 2018); (3) advanced technologies and components of the electrical network (Navigant Research, 2014); (4) integrated interfaces and decision support methods, energy demand management technologies, distributed monitoring and control systems; (5) integrated communications (Lee et al., 2017).

Therefore, one of the problems of introducing the components of the digital economy is the universalization, unification, and standardization of terminal devices - suppliers of the monitored information.

\section{Methods}

In terms of the intellectualization of data collection systems for the digital economy, special attention is paid not only to devices and individual sensors but also to system-wide efficiency. With the increase in the volume of transmitted data and the use of IoT, new problems arise due to the fact that: computational capabilities with linear growth of centralized cloud computing cannot meet the needs of processing data from several data sources simultaneously; network bandwidth and data transfer speeds have become a weak point due to the increase in the number of users; most end users are usually mobile devices that do not have enough computing resources to store and process large amounts of information.

Energy companies also face the necessity to introduce new standards of operation and maintenance to continuously improve the balance between supply reliability and costs. An important parameter is the quality of electricity, which determines the compatibility and features of the equipment. The standard values of power 
quality indicators (PQI) and their list are established by the standards (in the European Union - EN 50160, IEC 61000-4-30: 2008; in Russia - GOST R 54149, GOST 13109-97, etc.), which are the guideline for the developers (Zhornyak et al., 2010; de Andrade et al., 2019).

Another key problem in the energy sector is the protection of electrical equipment. Table 1 shows the results of a comparative analysis of electrical equipment protection technologies operating in the residential and industrial infrastructure. All this determines the set of methods used to ensure system-wide energy efficiency (Tupchienko, 2018; Zhornyak et al., 2010).

Table 1. Indicators for assessment of the electrical equipment protection technologies

\begin{tabular}{|c|c|c|}
\hline Protection & Housing infrastructure & Industrial infrastructure \\
\hline Overload & $\begin{array}{l}\text { Differential machines } \\
\text { Surge suppressors } \\
\text { Relays of voltage control } \\
\text { Thermal relays } \\
\text { Circuit breakers }\end{array}$ & $\begin{array}{l}\text { Current protection (electromagnetic relays, } \\
\text { semiconductor circuit breaker releases) } \\
\text { Temperature protection (thermal releases, electrothermal } \\
\text { relays) }\end{array}$ \\
\hline Short-circuit (SC) & $\begin{array}{l}\text { Differential machines } \\
\text { Circuit breakers } \\
\text { Fuses }\end{array}$ & $\begin{array}{l}\text { Fuses } \\
\text { Circuit breakers } \\
\text { Current cut-off (electromagnetic primary relay indirect } \\
\text { action) }\end{array}$ \\
\hline Leakage & $\begin{array}{l}\text { Residual current devices (RCDs) } \\
\text { Differential machines }\end{array}$ & Differential current devices (DCDs) \\
\hline Lightning & Lightning protection & Lightning protection \\
\hline Reactive power compensation & Not used & Filter compensating devices (FCDs) and \\
\hline $\begin{array}{l}\text { Asymmetry and non- } \\
\text { sinusoidality of current and } \\
\text { voltage curves }\end{array}$ & Surge protectors & Filter balancing devices (FBDs) \\
\hline Voltage dips (ACF) & $\begin{array}{l}\text { Surge protectors } \\
\text { Relays of voltage control }\end{array}$ & $\begin{array}{l}\text { Devices for automatic power reserve switch-on } \\
\text { (DAPRSOs) }\end{array}$ \\
\hline $\begin{array}{l}\text { Arc-over and combustion } \\
\text { occurrence }\end{array}$ & $\begin{array}{l}\text { Arc-over detection protection devices } \\
\text { (ADPDs) }\end{array}$ & Arc-over detection protection devices (ADPDs) \\
\hline
\end{tabular}

According to the results of a comparative analysis of electrical equipment protection technologies operating in the housing and industrial infrastructure, the following conclusions can be drawn:

- protection technologies operating at power industry enterprises are more complex than in housing infrastructure;

- for housing infrastructure, the greatest coverage from various types of protection is provided by the differential machine, able to constitute the main component of the infrastructure based on smart machines and IoT principles.

As an example, let us consider in more detail the concept of implementing a universal smart machine (developed by LLC "Connect", Russia) as a technological element for the development of the energy infrastructure in the digital economy.

\section{Results}

The analysis of the problems in the field of intellectualization of the energy sector infrastructure in the digital economy shows that the necessity of creation of simple, universal, intelligent smart machines, as the terminal elements of the global Smart Grid system, becomes obvious. A universal smart machine should constructively be 
a device in a form-factor of a circuit breaker that implements certain triggering algorithms. Let us analyze the main characteristics of such devices and the requirements for them.

Intelligent data collection systems in the energy sector include the following units: (1) automated systems, such as an automated information and measurement system for electricity metering, a dispatch control system, a process control system; (2) results of control measurements, meter readings for non-automatic collection of information, instrument readings for measurement and control.

The concept of implementing an intelligent smart machine for the intellectualization of the infrastructure of the energy sector includes two main functional units: an integrated power protection unit and a unit for monitoring its parameters (Figure 3) (Zhornyak et al., 2010; de Andrade et al., 2019; Nafi et al., 2016). Modern complex power supply protection should include: protection against cable overheating, protection against short circuits, protection against sparking, protection against significant voltage deviations, protection against current leakage. The monitoring function is focused on the ability to control parameters such as voltage, current, power, and power consumption. In addition, monitoring in intelligent protection systems should allow determining the state of the system and the cause of the shutdown.

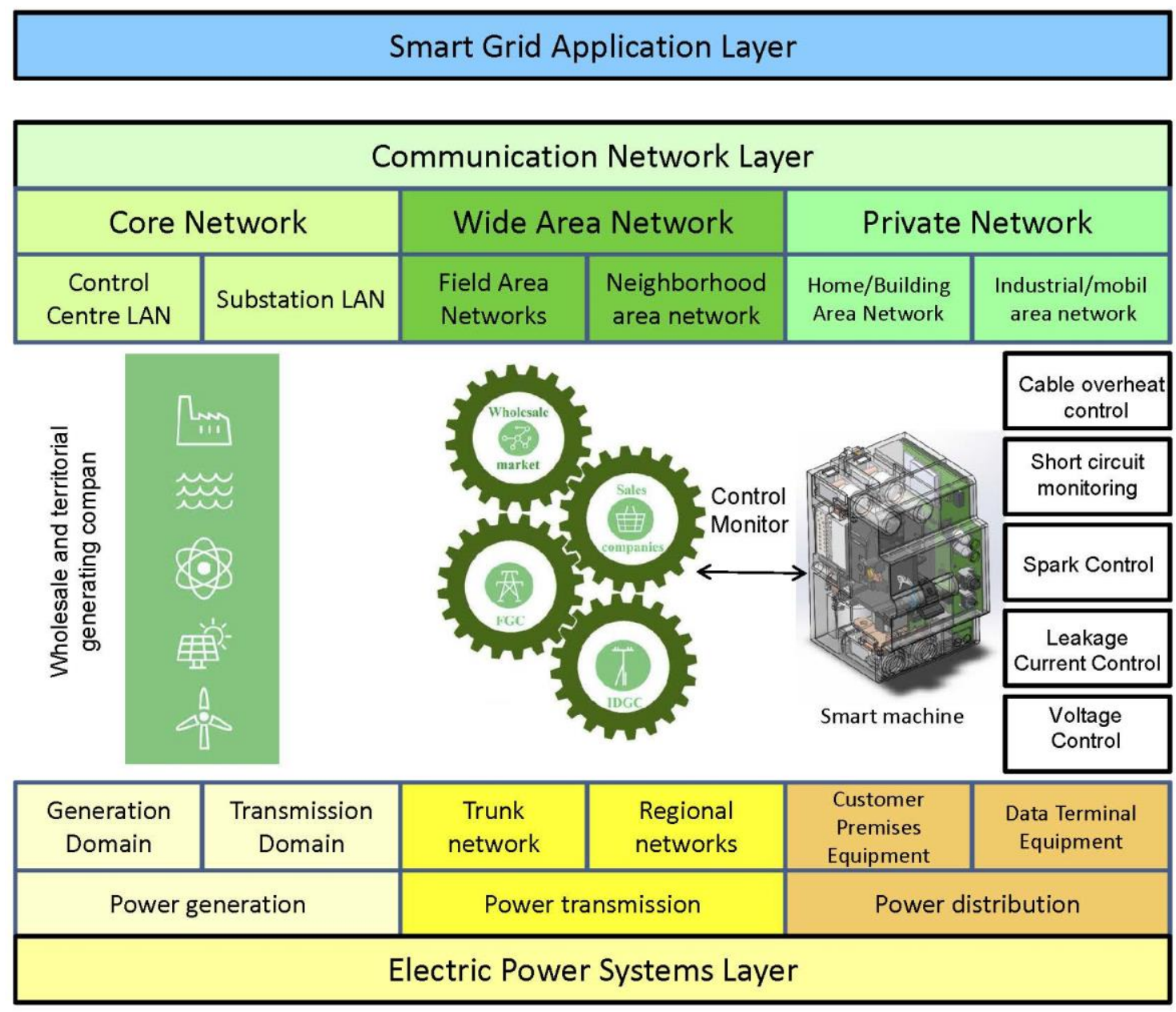

Fig. 3. Functional diagram of the integration of smart machines in the intelligent energy infrastructure (as illustrated by Russia) 


\section{ENTREPRENEURSHIP AND SUSTAINABILITY ISSUES}

ISSN 2345-0282 (online) http://jssidoi.org/jesi/

2019 Volume 6 Number 4 (June)

http://doi.org/10.9770/jesi.2019.6.4(..)

Figure 3 shows the interaction of integrated power system components as illustrated by Russia, where the companies of various types are represented (Kuzmin et al., 2019). The wholesale market provides the opportunity for large buyers of electricity and power to purchase it directly from generating companies. The grid companies manage the Unified National Electric Grid, provide services for electricity transmission within the trunk and interregional networks to producers. Individual sales companies interact with the end consumers, which provide accounting and management of operating modes. The main task of the work is to determine the role and analysis of specific options for the implementation of universal, intelligent smart machines that interact with specific consumers. The functions of the Control Monitor at the end-user level, implemented by the smart-machine, assume: State (on/off); Electricity consumption in $\mathrm{kWh}$; Power supply voltage; Line current consumption; Cause of shutdown (overload/short circuit/leakage current/arcing).

One of the strategic objectives of the implementation of the Smart Grid is to reduce the losses at all levels of generation, transmission, and consumption of electricity and to ensure the set level of quality. At the same time, the quality of electrical energy and reliability of electric power systems are characterized by standardized indicators. The data on the electrical network is taken at the first stage of the power quality analysis algorithm. Further, two sets of tasks are carried out in parallel: quality control of the electrical network and power consumption control. In a formalized form, the list of properties of the electrical energy quality can be represented as a diagram (Figure 4) (de Andrade et al., 2019).

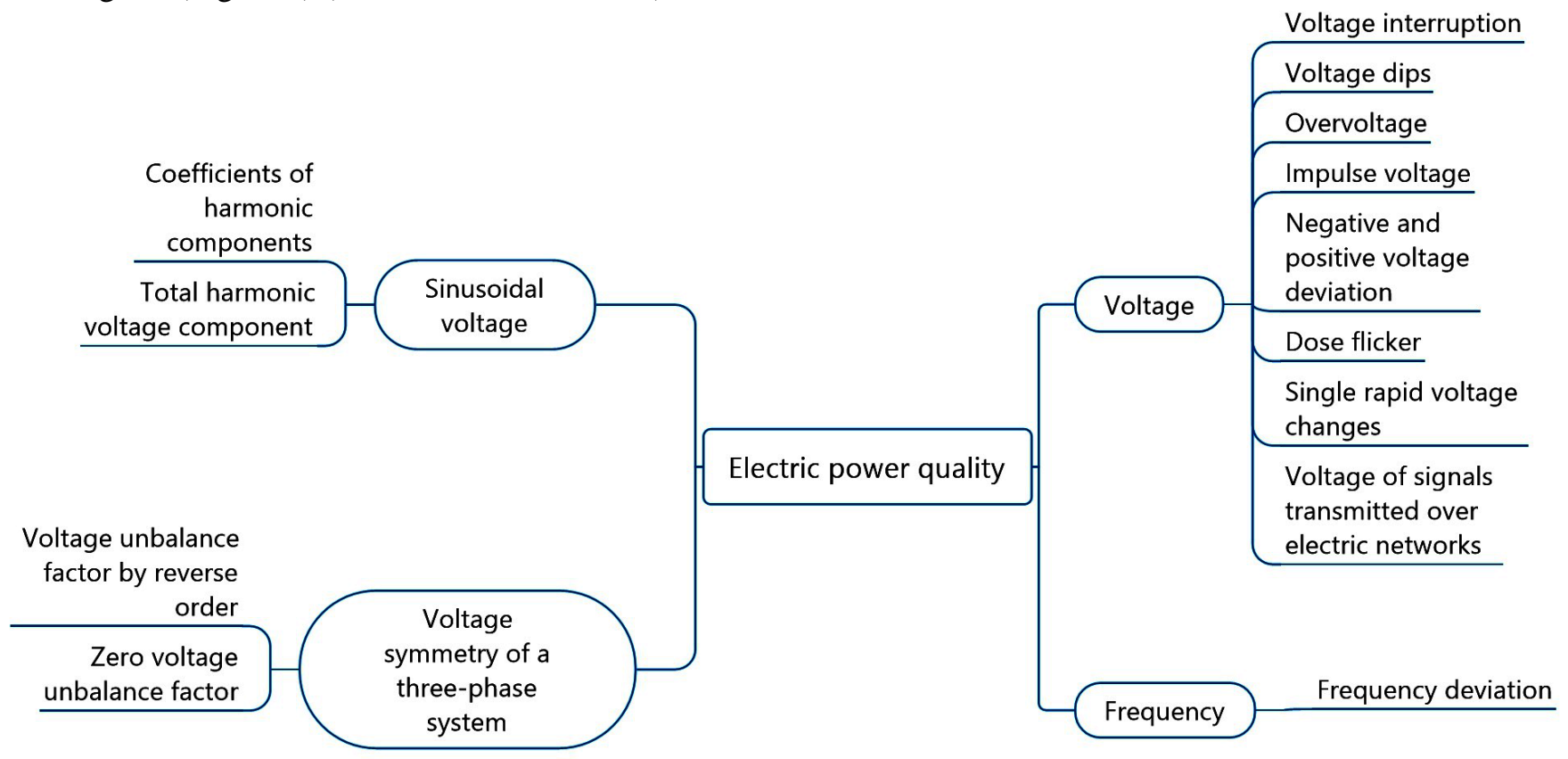

Fig. 4. Power quality indicators taken into account in smart data collection systems

To create a basis for the development of infrastructure by the example of the energy industry in terms of digitalization, it is proposed to implement the integrated monitoring of the local parameters of the power grid performed on the basis of a multifunctional protection device made in the form of a single device (intelligent smart machine). This solution is qualitatively different from the existing systems in terms of size, cost, and complexity of installation. The integration of intellectual functions of control and monitoring into protection systems will ensure the fast introduction of modern digital technologies into the residential and industrial infrastructure. Smart machines are the basic element that implements such an integration.

A power quality control system includes the following components: 


\section{ENTREPRENEURSHIP AND SUSTAINABILITY ISSUES}

ISSN 2345-0282 (online) http://jssidoi.org/jesi/

2019 Volume 6 Number 4 (June)

http://doi.org/10.9770/jesi.2019.6.4(..)

- measuring components (measuring voltage transformers - MVTs, measuring current transformers - MCTs);

- complex components, measuring and computing complexes (meters of power quality indicators -MPQIs, software and hardware complexes of electricity quality control - PTCs);

- connecting components (communication lines between instrument transformers and PQI meters, GSM modems, equipment and Ethernet networks, concentration units - HUBs);

- computational components (data servers, data collection stations and workstations with installed system and application software).

The requirements systematized in Table 2 are the basis for the design of universal smart machines as data collection devices. They define the approaches to the implementation of the software, hardware and design solutions that provide diagnostics and monitoring of the energy state of infrastructures, individual and collective energy systems, life support of buildings, the state of household appliances, IoT devices, and housing and communal services (Eneca, 2018).

Table 2. Functional characteristics of the smart machine, monitoring and control system, information system

\begin{tabular}{|c|c|}
\hline $\begin{array}{l}\text { Component of the } \\
\text { technology subbase }\end{array}$ & Functions of the component \\
\hline \multirow{11}{*}{ Smart machine } & $\begin{array}{l}\text { Continuous reading of the main indicators taken from the electrical network (analysis of the mains voltage, } \\
\text { parameters of the flowing current, power consumption) }\end{array}$ \\
\hline & $\begin{array}{l}\text { Continuous analysis of the main indicators taken from the electrical network (analysis of the mains voltage, } \\
\text { parameters of the flowing current, power consumption) }\end{array}$ \\
\hline & $\begin{array}{l}\text { Continuous quality control of the main indicators taken from the electrical network (analysis of the mains } \\
\text { voltage, parameters of the flowing current, power consumption) to identify the scenario of exceeding the } \\
\text { allowable thresholds for automatic shutdown }\end{array}$ \\
\hline & $\begin{array}{l}\text { Continuous monitoring of the frequency of the alternating current on the amplitude-time characteristics of the } \\
\text { electrical signal to identify the scenario of a spark in the conductor for automatic shutdown }\end{array}$ \\
\hline & Network protection based on the principles of the differential machine, AFDD and the Internet of things \\
\hline & Implementation of automatic shutdown technology \\
\hline & $\begin{array}{l}\text { Implementation of forced disconnection technology according to the message received from the monitoring } \\
\text { and control system }\end{array}$ \\
\hline & Urgent notification of the monitoring and control system \\
\hline & Continuous provision of data on the operation of monitored devices to the monitoring and control system \\
\hline & Continuous reception of messages for forced disconnection from the monitoring and control system \\
\hline & Receipt of the executive decisions on normalization from the monitoring and control system \\
\hline \multirow{11}{*}{$\begin{array}{l}\text { Monitoring and } \\
\text { control system }\end{array}$} & $\begin{array}{l}\text { Analysis of current and voltage to identify the forced shutdown scenarios for the smart machine in case of } \\
\text { exceeding the threshold values }\end{array}$ \\
\hline & $\begin{array}{l}\text { Leakage current analysis to identify the forced shutdown scenario for the smart machine in case of exceeding } \\
\text { the threshold values }\end{array}$ \\
\hline & $\begin{array}{l}\text { Analysis of the alternating current frequency by the amplitude-time characteristics of the electrical signal to } \\
\text { identify the scenario of the appearance of a spark in the conductor and forced shutdown of the smart machine }\end{array}$ \\
\hline & $\begin{array}{l}\text { Analysis of the loading of the three-phase power supply phases to identify a skew scenario with the possibility } \\
\text { of forming a normalization decision }\end{array}$ \\
\hline & Transfer of the shutdown message to the smart machine \\
\hline & Transfer of executive normalization solutions to the smart machine \\
\hline & $\begin{array}{l}\text { Reporting on the significance of the main indicators at the facilities (elements) of the residential and small } \\
\text { industrial infrastructure }\end{array}$ \\
\hline & $\begin{array}{l}\text { Reporting on the emergency situations at the facilities (elements) of the residential and small industrial } \\
\text { infrastructure }\end{array}$ \\
\hline & Receipt of the messages from the information system \\
\hline & $\begin{array}{l}\text { Notification of the information system about the emergency situation with the objects (elements) of the } \\
\text { housing and small industrial infrastructure }\end{array}$ \\
\hline & $\begin{array}{l}\text { Information system data transfer from the objects (elements) of the residential and small industrial } \\
\text { infrastructure }\end{array}$ \\
\hline
\end{tabular}


ENTREPRENEURSHIP AND SUSTAINABILITY ISSUES

ISSN 2345-0282 (online) http://jssidoi.org/jesi/

2019 Volume 6 Number 4 (June)

http://doi.org/10.9770/jesi.2019.6.4(..)

\begin{tabular}{|l|l|}
\hline $\begin{array}{c}\text { Component of the } \\
\text { technology subbase }\end{array}$ & \multicolumn{1}{|c|}{ Functions of the component } \\
\hline \multirow{5}{*}{ Information system } & $\begin{array}{l}\text { Receipt of data from the monitoring and control system about the value of the main parameters of current, } \\
\text { voltage and power consumption from objects (elements) of residential and small industrial infrastructure }\end{array}$ \\
\cline { 2 - 3 } & $\begin{array}{l}\text { Receipt of the notifications from the monitoring and control system about the emergency situation with the } \\
\text { objects (elements) of the housing and small industrial infrastructure }\end{array}$ \\
\cline { 2 - 2 } & $\begin{array}{l}\text { Storage of the data on the values of the basic parameters of current, voltage and power consumption from the } \\
\text { objects (elements) of housing and small industrial infrastructure }\end{array}$ \\
\cline { 2 - 2 } & $\begin{array}{l}\text { Analysis, including predictive one, of the obtained data on the value of the main parameters of current, voltage } \\
\text { and power consumption from the facilities (elements) of the residential and small industrial infrastructure }\end{array}$ \\
\cline { 2 - 2 } & $\begin{array}{l}\text { Analysis of the functioning of the algorithms implemented by the smart machine and the monitoring and } \\
\text { control system }\end{array}$ \\
\cline { 2 - 2 } & Reporting \\
\cline { 2 - 2 } & Alert on abnormal situation objects (elements) of housing and small industrial infrastructure \\
\hline
\end{tabular}

\section{Discussion}

The result of the research is the concept of implementation of an intelligent smart machine in the energy sector. The proposed concept of a smart machine differs from the well-known analogs in that it is a comprehensive solution to ensure the protection of power grids with built-in intellectual functions, including the functions of monitoring parameters. This solution makes it possible to perform the transition to a digital economy in the residential and industrial power industry quickly and at minimum expense, since no individual installation of intelligent control and monitoring elements is required, while the installation and replacement of the security systems are carried out regularly with a certain frequency. In the long term, the monitoring function will make it possible both to reduce final energy consumption, by controlling the demand, and to improve the quality of electricity with reduced losses, by simplifying the search for the causes of deterioration. Figure 5 gives a predictive estimate of the possible effect of the introduction of Smart Grid systems based on smart machines, according to pilot Smart Grid projects, which have been launched in various countries (Navigant Research, 2014; Eneca, 2018; TAdviser, 2018; Nafi et al., 2016). It should be noted that for many reasons, there is extremely high uncertainty of the expected effects of the introduction (Navigant Research, 2014; Eneca, 2018; TAdviser, 2018).

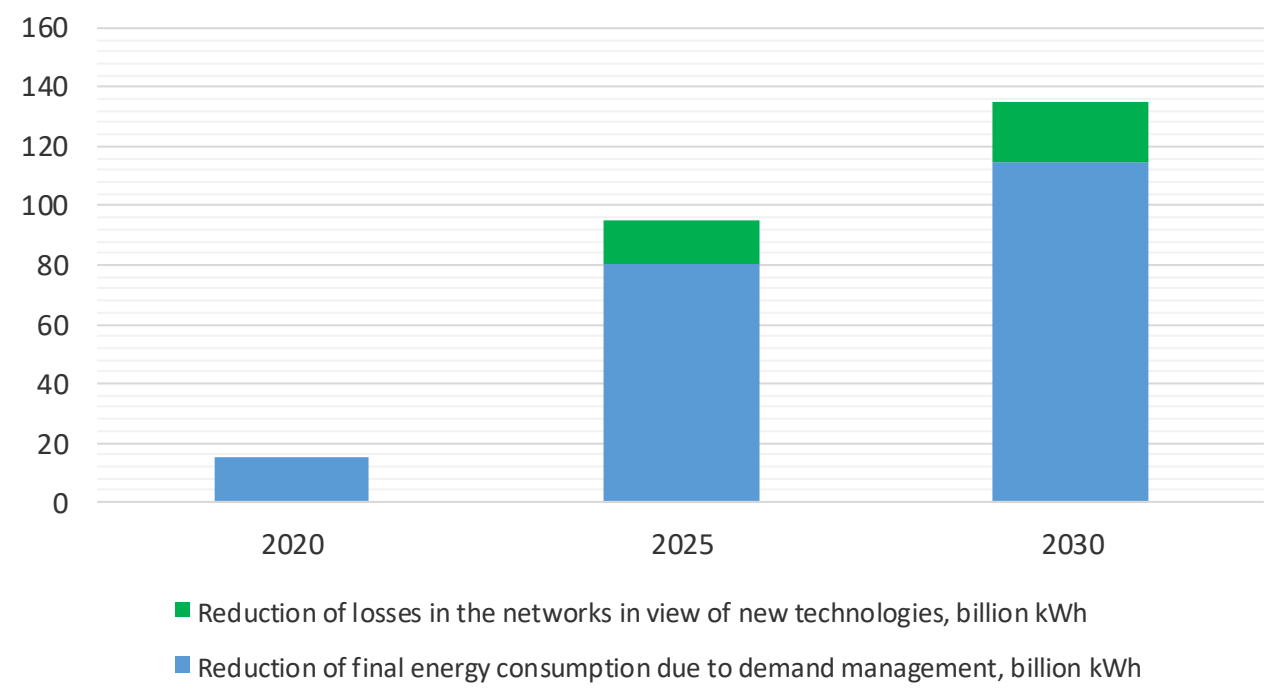

Fig. 5. Predictive assessment of energy consumption reduction due to the implementation of Smart Grid systems based on smart machines 


\section{ENTREPRENEURSHIP AND SUSTAINABILITY ISSUES}

ISSN 2345-0282 (online) http://jssidoi.org/jesi/

2019 Volume 6 Number 4 (June)

http://doi.org/10.9770/jesi.2019.6.4(..)

Thus, the results of the creation of a smart meter (a special case of a smart machine), or the technological basis for the development of innovative housing infrastructure is a comprehensive solution and is based on basic digital technologies (Figure 1). For normal operation, a smart meter must have an interface for interaction with an automated information-measuring system for commercial metering of electricity. Such a system in general is a combination of hardware and software that provides for the remote collection, storage, and processing of data on energy flows in power grids. It is necessary for the automation of power management and also performs the technical functions of monitoring the operating modes of electrical equipment.

Comparative evaluation of interfaces and protocols for the implementation of the interaction of a smart meter (intelligent smart machine in general) with monitoring and control devices showed that:

- there is a wide variety of technologies, protocols, and standards for communicating IoT devices even within the same industry (utilities/smart meters, transportation, industry, etc.) and none of the existing protocols is the only candidate for the universal protocol for all devices accounting;

- in each industry, there are specific requirements corresponding to the tasks and needs to be solved, in this regard, the development of common universal technological communication standards for the market of the Internet of Things in general is hardly feasible and possible; however, on the other hand, a set of key technologies, protocols, and standards is required for each vertical market and, possibly, its separate segments;

- it is necessary to shrink from closed protocols and interfaces to standards-based solutions;

- if there is a task of monitoring and metering of electricity in the wholesale and retail markets (for example, monitoring of transformer substations), then special attention should be paid to solutions based on standardized protocols. These protocols are well suited for this task. Such a protocol can be used when transferring data from electricity meters/DATDs to the upper level (SCADA system, AMRCS);

- the analysis of the protocols for compatibility showed that the Modbus family of protocols can be used in the residential sector. It is widely used in industry, it is universal and in demand in utilities. Today, the equipment from almost all manufacturers supports Modbus protocols;

- the PLC protocol is preferable when collecting data on the consumed electricity from the lower level (from electricity meters);

- the use of metering devices with MBUS is fully justified for the residential construction of the premium segment ("smart" buildings). At the same time, the accounting system on MBUS can be harmoniously integrated into the existing automation system based on the KNX bus, which will provide complete and transparent automation from top to bottom. It is possible to use MBUS for ordinary housing, but here the not too high prevalence of this protocol will act as a retarding factor, and as a result, it will be linked to the selected vendor once.

According to the research results, it can be stated that universal smart automata are the ultimate element of data collection in the digital economy. Using the example of the energy sector, it can be noted that the use of such smart machines in the residential and industrial infrastructure provides high-quality diagnostics and monitoring of individual and collective energy supply systems.

\section{Conclusion}

The proposed concept of a universal smart machine provides diagnostics and monitoring of individual and collective power supply systems, building life support, the state of consumer devices, IoT devices, and devices of the housing and utilities sector. As part of the technological solution, this device implements comprehensive protection of the electrical network. In addition to the basic protection functions, the smart machine will make it easier to record data on electricity consumption, quality of power supply, reduce the number of emergency situations, by simplifying their diagnostics. The proposed conceptual solutions open up opportunities for 


\section{ENTREPRENEURSHIP AND SUSTAINABILITY ISSUES}

ISSN 2345-0282 (online) http://jssidoi.org/jesi/

2019 Volume 6 Number 4 (June)

http://doi.org/10.9770/jesi.2019.6.4(..)

improving the efficiency of design technologies and creating energy-efficient objects, providing industry and households with new information services in the control over energy infrastructure.

\section{References}

Akberdina, V.V., Tretyakova, O.V., \& Vlasov, A.I. (2017). A Methodological Approach to Forecasting Spatial Distribution of Workplaces in an Industrial Metropolis. Problems and Perspectives in Management, 15(4), 50-61. https://doi.org/10.21511/ppm.15(4).2017.05

Andreev, K.A., Shakhnov, V.A., \& Vlasov, A.I. (2016). Silicon Pressure Transmitters with Overload Protection. Automation and Remote Control, 77(7), 1281-1285. https://doi.org/10.1134/S0005117916070146

Barman, A., \& Ahmed, H. (2015). Big Data in Human Resource Management - Developing Research Context. https://doi.org/10.13140/RG.2.1.3113.6166

Berdyugina, O.N., Krivoshein, A.I., \& Vlasov, A.I. (2018). Technological Platform for Innovative Social Infrastructure Development on Basis of Smart Machines and Principles of Internet of Things. In 2018 Global Smart Industry Conference (GloSIC) (pp. 1-7). https://doi.org/10.1109/glosic.2018.8570062

de Andrade, L.C.M., Nanjundaswamy, T., Oleskovicz, M., Fernandes, R.A.S., \& Rose, K. (2019). Advances in Classification and Compression of Power Quality Signals. Journal of Control, Automation and Electrical Systems, 30, 402. https://doi.org/10.1007/s40313$\underline{019-00446-1}$

Edelev, A.V., Senderov, S.M., Beresneva, N.M., Sidorov, I.A., \& Feoktistov, A.G. (2018). Distributed Computing Environment for Analyzing the Vulnerability of Critical Infrastructures in the Power Industry. Control Systems, Communications and Security, 3, 197-231. https://doi.org/10.2991/iwci-18.2018.7

Eneca. (2018). SmartGrid. Retrieved November 29, 2018, from https://www.eneca.by/ru_smartgrid0/

Grigoriev, P.V., Krivoshein, A.I., Shakhnov, V.A., Filin, S.S., Migalin, V.S., \& Vlasov, A.I. (2018). Smart Management of Technologies: Predictive Maintenance of Industrial Equipment Using Wireless Sensor Networks. Entrepreneurship and Sustainability Issues, 6(2), 489502. http://doi.org/10.9770/jesi.2018.6.2(2)

Khelifi, F., Bradai, A., Benslimane, A., Rawat, P., \& Atri, M. (2018). A Survey of Localization Systems in Internet of Things. Mobile Networks and Applications, 1-25. https://doi.org/10.1007/s11036-018-1090-3

Kireev, V.S., Filippov, S.A., Guseva, A.I., Bochkaryov, P.V., Kuznetsov, I.A., \& Migalin, V. (2018a). Cloud Computing in Housing and Utility Services Monitoring Systems. In Proceedings - 2018 6th International Conference on Future Internet of Things and Cloud Workshops, W-FiCloud 2018 (pp. 90-94). IEEE. https://doi.org/10.1109/W-FiCloud.2018.00020

Kireev, V.S., Filippov, S.A., Guseva, A.I., Bochkaryov, P.V., Kuznetsov, I.A., Migalin, V., \& Filin, S.S. (2018b). Predictive Repair and Support of Engineering Systems Based on Distributed Data Processing Model within an IoT Concept. In Proceedings - 2018 6th International Conference on Future Internet of Things and Cloud Workshops (FiCloudW) (pp. 84-89). IEEE. https://doi.org/10.1109/W$\underline{\text { FiCloud.2018.00019 }}$

Kuzmin, E.A., Volkova, E.A., \& Fomina, A.V. (2019). Research on the Concentration of Companies in the Electric Power Market of Russia. International Journal of Energy Economics and Policy, 9(1), 130-136. https://doi.org/10.32479/ijeep.7169

Lee, C.K.M., Zhang, S.Z., \& Ng, K.K.H. (2017). Development of an Industrial Internet of Things Suite for Smart Factory towards ReIndustrialization. Advances in Manufacturing, 5(4), 335-343. https://doi.org/10.1007/s40436-017-0197-2

Lyapin, A.M., \& Finogeev, A.G. (2016). Technologies BIGDATA and Cloud Computing for Monitoring Energy Facilities in the Field of Housing And Communal Services. News of Volgograd State Technical University, 3(182), 53-58.

Nafi, N.S., Ahmed, K., Gregory, M.A., \& Datta, M. (2016). A Survey of Smart Grid Architectures, Applications, Benefits and Standardization. Journal of Network and Computer Applications, 76, 23-36. https://doi.org/10.1016/j.jnca.2016.10.003 


\section{ENTREPRENEURSHIP AND SUSTAINABILITY ISSUES}

ISSN 2345-0282 (online) http://jssidoi.org/jesi/

2019 Volume 6 Number 4 (June)

http://doi.org/10.9770/jesi.2019.6.4(..)

Navigant Research. (2014). Executive Summary: Smart Cities Smart Technologies and Infrastructure for Energy, Water, Transportation, Buildings, and Government: Business Drivers, City and Supplier Profiles, Market Analysis, and Forecasts. Navigant Consulting, Inc. Retrieved November 30, 2018, from http://boletines.prisadigital.com/smartcities.pdf

Petrenko, Y., Vechkinzova, E., \& Antonov, V. (2019). Transition from the industrial clusters to the smart specialization of the regions in Kazakhstan. Insights into Regional Development, 1(2), 118-128. https://doi.org/10.9770/ird.2019.1.2(3)

Rentiuk, V.A. (2017). Brief Guide to the Internet of Things Wireless Technologies. Part 1. Networks, Gateways, Clouds and Protocols. Control Engineering Russia, 6(72), 61-65.

Roslyakov, A.V., Vanyashin, S.V., \& Grebeshkov, A.Yu. (2015). The Internet of Things (pp. 107-109). Samara: PGUTI.

Swan, M. (2015). Blockchain: Blueprint for a New Economy. O'Reilly Media, Inc. (p. 132).

TAdviser. (2018, December 20). Smart Grids. Retrieved April 29, 2019, from http://www.tadviser.ru/index.php/Статья:Smart_Grid_\%28Умные_Сети\%29

Tupchienko, V.A. (Ed.). (2018). Digital Platforms for Lifecycle Management of Complex Systems. Moscow: Nauchniy konsultant. (p. 440).

Vasiliev, V.A., \& Chernov, P.S. (2012). Smart Sensors, Sensor Networks and Digital Interfaces. Measuring Equipment, 10, 3-6.

Vlasov, A.I., Yudin, A.V., Salmina, M.A., Shakhnov, V.A., \& Usov, K.A. (2017). Design Methods of Teaching the Development of Internet of Things Components with Considering Predictive Maintenance on the Basis of Mechatronic Devices. International Journal of Applied Engineering Research, 12(20), 9390-9396.

Zhornyak, L.B., Erzh, T.A., Osinskaya, V.I., \& Barannik, S.O. (2010). The Study of Modeling Methods to Improve the Quality of Electrical Energy in the Systems of Power Supply of Electricity Consumers. Electrical Engineering \& Electromechanics, 2.

\section{Aknowledgements}

This research was conducted with the support of the Ministry of Science and Education of Russia within the framework of the project under Agreement No. 14.579.21.0158, ID RFMEFI57918X0158.

Andrey I. VLASOV, Cand.Sci. (Engineering), Associate professor of the department IU4 "Designing and Technology of Electronic Equipment", assistant manager as IU4 chair on scientific work of the Bauman Moscow State Technical University (Moscow, Russian Federation). Research interests: neural networks, stable operating systems, Internet of things (IoT), public-private partnerships, economic sustainability.

ORCID ID: orcid.org/0000-0001-5581-4982

Vadim A. SHAKHNOV, Corresponding member of RAS, Dr.Sci. (Engineering), Professor, Head of the department IU4 "Designing and Technology of Electronic Equipment" of the Bauman Moscow State Technical University (Moscow, Russian Federation). Research interests: multidimensional data, industrial production, technological control, modeling and optimization of processes, knowledge management, professional education.

ORCID ID: orcid.org/0000-0003-4013-1905

Sergey S. FILIN, Technical Director of the LLC "Connect" (Moscow, Russian Federation). Research interests: industrial production, stable operating systems, Internet of things (IoT).

ORCID ID: orcid.org/0000-0002-6385-0454

Aleksey I. KRIVOSHEIN, Lead Engineer LLC “Connect” (Moscow, Russian Federation); Postgraduate student of the department IU4 "Designing and Technology of Electronic Equipment" of the Bauman Moscow State Technical University (Moscow, Russian Federation). Research interests: technology predictive industrial maintenance, system analysis, modeling and optimization of processes.

ORCID ID: orcid.org/0000-0001-8292-452X 
ENTREPRENEURSHIP AND SUSTAINABILITY ISSUES

ISSN 2345-0282 (online) http://jssidoi.org/jesi/

2019 Volume 6 Number 4 (June)

http://doi.org/10.9770/jesi.2019.6.4(..)

Register for an ORCID ID:

https://orcid.org/register

Copyright (C) 2019 by author(s) and VsI Entrepreneurship and Sustainability Center

This work is licensed under the Creative Commons Attribution International License (CC BY).

http://creativecommons.org/licenses/by/4.0/

(c) (i) Open Access 